\title{
ALBA-TCP: hacia nuevos mecanismos de participación de la economía social y solidaria
}

\author{
Carmen Rosa Schaposnik*, Eugenia Candelaria Pardo ${ }^{\star *}$
}

\footnotetext{
Especialista en Políticas de Integración, investigadora del Instituto de Integración Latinoamericana de la Universidad Nacional de La Plata, Argentina. Correo electrónico: rosasnik@yahoo.com.ar

** Magíster (c) en Integración Latinoamericana. Docente de la cátedra de Economía Política en la Facultad de Ciencias Jurídicas y Sociales, investigadora del Instituto de Integración Latinoamericana de la Universidad Nacional de La Plata, Argentina. Correo electrónico: eugeniacpardo@yahoo.com.ar
}

Recibido: 14 de marzo del 2015 Aprobado: 30 de abril del 2015

Cómo citar este artículo: Schaposnik, C. R. y Pardo, E. C. (2015). ALBA-TCP: hacia nuevos mecanismos de participación de la economía social y solidaria. Cooperativismo \& Desarrollo, 23(106), 35-44. doi: http://dx.doi. org/10.16925/co.v23i106.1129

\section{Resumen}

Propósito: el ALBA-TCP es una iniciativa de integración regional promovida por el ex presidente Hugo Chávez Frías que introduce la novedad de contemplar en sus mecanismos e instrumentos de cooperación un nuevo tipo de agenda social. Ello cobra significatividad en un mundo convulsionado desde la crisis global del 2007-2008 por la acción especulativa de grupos concentrados que desestabilizan las economías a escala mundial, y también, en una región como la latinoamericana y caribeña, donde coexisten visiones divergentes en relación con la integración regional. Descripción: el artículo propone, primero, realizar un repaso de la participación social en la institucionalidad del ALBA-TCP; luego, una revisión de los mecanismos de inserción de la economía social y solidaria, y por último, busca identificar el desafío que representa este nuevo tipo de agenda social. Punto de vista: desde una perspectiva descriptiva-interpretativa, se presentará la tensión intelectual que propone este modelo de integración junto con las posibilidades que se abren para la economía social y solidaria. Conclusiones: se pretende reflexionar a partir del reconocimiento de una realidad conflictiva, abierta y condicionada por el territorio, acerca de la necesidad de adelantar un trabajo conjunto de los científicos con los pueblos.

Palabras clave: agenda social, ALBA-TCP, economía solidaria, participación. 


\title{
ALBA-TCP: Towards New Mechanisms for Participation in the Social and Solidarity Economy
}

\begin{abstract}
Purpose: The ALBA-TCP is a regional integration initiative promoted by former president Hugo Chávez Frías that introduces the innovation of contemplating a new type of social agenda in its mechanisms and instruments for cooperation. This becomes significant in a world convulsed by the global crisis of 2007-2008 stemming from speculative action by concentrated groups that destabilize economies at the worldwide scale; also, in regions such as Latin America and the Caribbean, where there are divergent visions of regional integration. Description: The article first of all proposes to review social participation in the institutions of the ALBA-тCP; it then examines mechanisms for insertion of the social and solidarity economy; and finally, it seeks to identify the challenge posed by this new type of social agenda. Point of view: From a descriptive-interpretive perspective, it shows the intellectual tension proposed by this model for integration along with the possibilities that are opened for the social and solidarity economy. Conclusions: The aim is to reflect, based on recognition of a conflictive and open reality conditioned by the territory, regarding the need for joint work by scientists with the peoples.
\end{abstract}

Keywords: social agenda, ALBA-TCP, solidarity economy, participation.

\section{ALBA-TCP: rumo a novos mecanismos de participação da economia social e solidária}

\section{Resumo}

Propósito: o ALBA-TCP é uma iniciativa de integração regional promovida pelo ex-presidente Hugo Chávez Frías, que introduz a novidade de contemplar em seus mecanismos e instrumentos de cooperação um novo tipo de agenda social. Isso ganha sentido num mundo convulsionado desde a crise global de 2007-2008 pela ação especulativa de grupos concentrados que desestabilizam as economias em escala mundial e também numa região como a latino-americana e a caribenha, onde coexistem visões divergentes sobre a integração regional. Descrição: este artigo propõe, primeiramente, realizar uma revisão da participação social na institucionalidade da ALBA-TCP; em seguida, uma revisão dos mecanismos de inserção da economia social e solidária; finalmente, busca identificar o desafio que representa esse novo tipo de agenda social. Ponto de vista: de uma perspectiva descritiva-interpretativa, será apresentada a tensão intelectual que esse modelo de integração propõe junto com as possibilidades que são abertas para a economia social e solidária. Conclusões: pretende-se refletir, a partir do reconhecimento de uma realidade conflitiva, aberta e condicionada pelo território, sobre a necessidade de um trabalho conjunto dos cientistas com a população.

Palavras-chave: agenda social, ALBA-TCP, economia solidária, participação. 


\section{Introducción}

La Alianza Bolivariana para los Pueblos de Nuestra América-Tratado de Comercio con los Pueblos (ALBATCP) se desarrolla en un contexto de complejidad internacional y regional, dado el proceso de reconfiguración del hemisferio, con modelos económicos dispares que fragmentan la región. Por cierto, se evidencian tres ejes: por un lado, el del "regionalismo abierto-TLC", centrado exclusivamente en el comercio -en el que podría incluirse la Alianza para el Pacífico (AP) - , por otro, dos que son críticos de este último: el "revisionista", cuya expresión la constituye la Unión de Naciones Suramericanas (Unasur) y el "eje anti-sistémico" representado por la iniciativa del ALBA-TCP (Briceño, 2011).

También, se visualiza la coexistencia de gobiernos progresistas críticos del consenso neoliberal que dan cuenta de una renovación en los estilos de intervención sobre la sociedad, así como aquellos de orientación más conservadora. Por ejemplo, entre los primeros están los que adhieren a una política económica heterodoxa, como Bolivia, Ecuador y Venezuela, entre otros, pero también los que continúan adhiriendo al neoliberalismo, como México, Colombia y Perú (Svampa, 2012).

Reconociendo las tensiones de este entramado social, político y económico para la integración regional, se propone analizar entonces, bajo una perspectiva descriptiva-interpretativa, la nueva agenda social del ALBA-TCP prevista en sus diversos mecanismos e instrumentos; así como las oportunidades de participación de la economía social y solidaria. Todo ello con el fin de construir en conjunto un nuevo paradigma de integración regional y poder contribuir para gestar políticas plurales a la medida de los pueblos.

\section{El ALBA-TCP y sus mecanismos de integración y cooperación}

En abril del 2015, cuando se escribió este artículo, los países latinoamericanos y caribeños que integraban el ALBA-TCP eran doce: Cuba y Venezuela (socios fundadores en el 2004), Bolivia (2006), Nicaragua (2007), Mancomunidad de Dominica (2008), Ecuador (2009), San Vicente y Las Granadinas (2009), Antigua y Barbuda (2009), Surinam (2012), Santa Lucía (2013), Granada y San Cristóbal y Nieves (2014), los que en conjunto representan una población heterogénea de más de
70 millones de habitantes y un PBI que supera los 460 millones de dólares.

Desde sus inicios, la Alianza se planteó como una propuesta innovadora en el campo de la integración regional, recuperando los ideales movilizadores de las luchas por la independencia de finales del siglo XVI y principios del XVII y todo el siglo XIX, a la vez que la literatura crítica de entonces. Fue el Presidente de Venezuela, Hugo Chávez Frías, que en febrero de 1999 presentó la iniciativa y comenzó así a gestarse la creación de un bloque regional:

En el cual la dimensión económica se vería sometida desde sus inicios a la dimensión política, que fue tomando forma cuando en la III Cumbre de la Asociación de Estados del Caribe (AEC) se propuso un ALBA en contraposición al ALCA (Schaposnik y Pardo, 2013, p. 45).

De manera formal, el ALBA arranca en diciembre del 2004, cuando en la I Cumbre los jefes de Estado de Venezuela y de Cuba suscriben en La Habana una declaración conjunta. Distintivamente se sustentó en el desarrollo de la cooperación y la integración en las áreas económica, comercial y productiva, con fuerte acento en la dimensión social. La estrategia adoptada, según Benzi (2010), se articula en cuatro ejes: el energético, con Petróleos del Caribe (Petrocaribe); el social, a través de las Misiones Sociales; el financiero, con el Banco del ALBA y el Sistema Unitario de Compensación Regional (SUCRE), entre otros, y el económico, asentados todos en una estructura institucional que se ha ido forjando a lo largo del tiempo.

Así, en el campo de la cooperación energética, el ALbA estructura a través de Petrocaribe, con el propósito de facilitar el acceso a los recursos energéticos mediante un intercambio favorable, equitativo y justo entre los países de la región caribeña y con el principal objetivo de "coordinar las políticas públicas en materia de energía de los países miembros" (Petróleos de Venezuela, S. A. [PDVSA], 2005, art. 2). Petrocaribe engloba a 18 estados centroamericanos y caribeños, a saber: Antigua y Barbuda, Bahamas, Belice, Cuba, Dominica, El Salvador', Granada, Guatemala,

El Salvador ingresó a Petrocaribe el 2 de junio del 2014, con aprobación unánime en la XIII Reunión del Consejo Ministerial. La adhesión no fue sometida por el poder ejecutivo a ratificación por parte de la Asamblea Legislativa de ese país, en virtud de considerar a Petrocaribe como un "foro" y no como un "organismo" internacional. 
Guyana, Haití, Honduras, Jamaica, Nicaragua, República Dominicana, San Cristóbal y Nieves, San Vicente y las Granadinas, Santa Lucía, Surinam, además de Venezuela.

Adicionalmente, dicho acuerdo contempló principios en sintonía con los del ALBA-TCP, esto es: unión, solidaridad, cooperación, complementariedad, seguridad energética, desarrollo socioeconómico, empleo Soberano de los recursos energéticos, visión conservacionista y mirada hacia el sur. Por ello, el Sistema Económico Latinoamericano y del Caribe (sElA, 2013) entiende que se basa en dos pilares: primero, la solidaridad de Venezuela, país superavitario en energía, con aquellos que tienen escasez de fuentes y recursos energéticos; y segundo, el reconocimiento de las asimetrías entre países con diferente desarrollo relativo. También, junto con PDvsA, pone en discusión la disyuntiva subyacente Estado-mercado.

Respecto al eje financiero, se destacan dos iniciativas: por un lado, el Banco del ALBA, creado en la VI Cumbre del 2008 con el fin de "coadyuvar al desarrollo económico y social sostenible, reducir la pobreza y las asimetrías", además de "fortalecer la integración, promover un intercambio económico justo, dinámico, armónico y equitativo entre los miembros del ALBA, inspirado en los principios de solidaridad, complementariedad, cooperación y respeto a la soberanía de los pueblos". Por el otro, el SUCRE, un mecanismo de pagos regional basado en la utilización de una moneda electrónica para las operaciones comerciales entre los países, que incluye la intermediación financiera y la generación de créditos orientados al desarrollo de la producción exportable, abriendo las posibilidades de inserción comercial a los pequeños y medianos productores y a las empresas de la economía social. Ellos se proponen como parte de una nueva arquitectura financiera regional (NARF) alternativa al FMI, BM, BID y a los mecanismos de compensación gestados en el siglo $\mathrm{xx}$; ya sea porque en el caso del Banco el poder de voto es independiente del capital aportado por cada país, o porque el SUCRE busca desacoplarse del uso de la moneda norteamericana en las transacciones comerciales (Schaposnik y Pardo, 2009, 2011b).

En el eje económico se destacan, por un lado, los proyectos y las empresas grannacionales PGN y EGN, destinados a promover la integración productiva regionalyla creación delEspacio Económico Ecoalba ${ }^{2}$, cuyo objeto, según el preámbulo del acuerdo de creación, es:

El ordenamiento y dinamización de las relaciones económicas entre los Países Signatarios, potenciando el encadenamiento productivo y comercial complementario [de modo tal que] permita el desarrollo pleno de las potencialidades y capacidades productivas en sectores prioritarios, a los fines de satisfacer las necesidades de los pueblos, atendiendo la demanda intrarregional y propiciando el escalamiento productivo, [a través de] la desgravación arancelaria, el énfasis en el intercambio de materias primas, bienes de capital e intermedios y de consumo final, [y la aplicación de] un conjunto de medidas que las incentiven, en función de los Planes de Desarrollo formulados por cada uno de los Países Signatarios (SELA, 2013, p. 17).

A la par, estos se articulan con los tratados de comercio con los pueblos (TCP), iniciativas surgidas en franca oposición a los tratados de libre comercio (TLC), por estar basados en la complementariedad, la solidaridad y la cooperación en el comercio, buscando ser parte de un desarrollo alternativo. Fueron anexados a la propuesta inicial del ALBA con oportunidad de la incorporación de Bolivia en la III Cumbre Ordinaria realizada en el 2006; más tarde, en la vi Cumbre se establecieron los principios que los rigen, afirmando que es fundamental impulsar el desarrollo integral socioproductivo, respetando los Derechos de la Madre Tierra, y contribuir decididamente a darle solución a la desigualdad y a la pobreza de nuestros pueblos.

Lo notable es que los TCP proponen un contenido diferente, sobre todo en relación con sus fines, el rol del Estado, a quienes benefician y a su contenido. En este sentido, en una entrevista, el ex embajador ante Naciones Unidas de Bolivia Pablo Solón resumió cuatro diferencias esenciales que los distinguen de los TLC, esquematizadas en la tabla 1.

2 El acuerdo para su creación se firmó en la XI Cumbre de febrero del 2012. En abril del 2013, en la viII Reunión del Consejo de Complementación Económica del ALBA-TCP, se acordó su texto definitivo por parte de Bolivia, Cuba, Ecuador, Nicaragua y Venezuela, el cual entró en vigencia en mayo del 2013. Su proyecto de complementación económica se inscribe en el marco normativo de la Aladi. 
Tabla 1

Diferencias entre los TLC y los TCP

\begin{tabular}{|c|c|c|}
\hline Diferencias & TLC & TCP \\
\hline 1. Fines & $\begin{array}{l}\text {-Buscan disminuir o eliminar aranceles, pero } \\
\text { ningún país elimina los aranceles para todos } \\
\text { los productos. }\end{array}$ & $\begin{array}{l}\text {-De acuerdo con el artículo 1: los gobiernos eliminan los aran- } \\
\text { celes y cualquier tipo de barrera comercial. Además, incluyen } \\
\text { compromisos de compra agrícola e industrial. }\end{array}$ \\
\hline $\begin{array}{l}\text { 2. Articulación } \\
\text { productiva }\end{array}$ & $\begin{array}{l}\text {-Fomentan la competencia entre productores } \\
\text { diametralmente distintos en relación con su } \\
\text { capacidad productiva. } \\
\text {-No existe la articulación productiva, solo } \\
\text { allanan la competencia entre empresas. }\end{array}$ & $\begin{array}{l}\text {-Fomentan la complementariedad productiva según las nece- } \\
\text { sidades de los países. Buscan crear proyectos, operaciones o } \\
\text { empresas binacionales. }\end{array}$ \\
\hline 3. Rol del Estado & $\begin{array}{l}\text {-Persiguen una participación cada vez menor } \\
\text { del Estado en el comercio. }\end{array}$ & $\begin{array}{l}\text {-Promueven la participación activa del Estado. El TCP señala la } \\
\text { importancia de la intermediación, el acopio y la comercialización. }\end{array}$ \\
\hline 4. Contenido & $\begin{array}{l}\text {-Tratan sobre cuestiones comerciales que en } \\
\text { teoría pueden ser aprovechadas por todos, } \\
\text { pero solo benefician a las grandes empresas } \\
\text { y a las trasnacionales. }\end{array}$ & $\begin{array}{l}\text {-Es reducido en extensión y omite los temas del TLC: propiedad } \\
\text { intelectual, servicios, etc., ya que deja a los Estados la potestad } \\
\text { sobre esos temas. } \\
\text {-Las normas buscan beneficiar a los sectores productivos } \\
\text { pequeños. } \\
\text {-Son acuerdos económicos asimétricos: el más grande concede } \\
\text { privilegios a los más chicos (trato diferenciado). }\end{array}$ \\
\hline
\end{tabular}

Nota. Elaboración propia con base en Solón (2006)

Lo anterior ilustra que los TLC por un lado, y los TCP por el otro, al igual que los otros mecanismos descritos, plantean incidencias distintas para los pueblos de la región en respuesta a las visiones diferentes de los procesos que los promueven (Schaposnik y Pardo, 2014).

\section{Las posibilidades de participación: hacia un nuevo tipo de agenda social}

El ALBA-TCP da relevancia en su institucionalidad a dos consejos: el Social y el de Movimientos Sociales. En conjunto, se sustentan en la solidaridad como uno de sus valores esenciales y la integración plena entre los pueblos es uno de sus objetivos centrales. Esta singularidad lleva a Silva (2011, p. 252) a sostener que así se facilita una "directa relación con el mejor apoyo a los objetivos del ALBA” permitiendo desarrollar una agenda no mercantilista y centrada en aspectos políticos, sociales, financieros y económicos.

En relación con los Consejos, por un lado el Consejo Social fue establecido en el 2009 en La Paz, cumpliendo con el mandato de la vi Cumbre Extraordinaria realizada el 24 de junio del 2009 en Maracay, Estado Aragua, Venezuela. Allí, los ministros del área social firmaron el Acta de instalación del Consejo con el fin de "instrumentar y hacer seguimiento a los Programas Sociales" y construir una agenda que "incorpore los temas de trabajo, vivienda y servicios básicos", sobre la base de la experiencia acumulada en el desarrollo de políticas sociales "de alto impacto" implementadas en el área de educación y salud (ALBA-TCP, 2009a). El Consejo está formado por los ministros de las áreas sociales de los países miembros, con dos niveles de funcionamiento (el ministerial y el técnico), además de grupos de trabajo que se ocupan de los temas de educación, salud, empleo, vivienda, cultura, deporte y, como subordinado, el Comité de la Mujer e Igualdad de Oportunidades.

Por otro, el Consejo de Movimientos Sociales ${ }^{3}$ es una muestra más del carácter innovador del ALBA-TCP. Remonta su origen a la v Cumbre, realizada en el 2007 en Tintorero, Venezuela, cuando se sugiere la construcción del espacio de integración no solo desde la institucionalidad de los gobiernos, sino a partir de la incorporación de estas formas de expresión social de los países signatarios del acuerdo. Se lo concibe como un mecanismo "que facilita la integración y participación social directa [y] tiene como misión articular a los Movimientos Sociales de los países miembros del ALBA-TCP y a aquellos de países no miembros, que se identifiquen con este esfuerzo" (ALBA-TCP, 2009b). Precisamente, en la XI Cumbre celebrada en febrero del 2012, estos movimientos

3 Lo integran básicamente aquellos movimientos sociales con capacidad de movilización popular, que sostienen una concepción antiimperialista, antineoliberal y luchan por la emancipación de la región. 
asumieron el compromiso de impulsar, en el ámbito productivo, modelos de propiedad social de los medios de producción, desde la base de la economía social, solidaria, comunitaria y comunal para el desarrollo de experiencias socioproductivas.

Es así como el ALBA-TCP, en virtud de escuchar y revalorizar el conocimiento de los pueblos, decididamente se aparta de encasillamientos teóricos clásicos en relación con la institucionalidad. Así, da lugar a que estas racionalidades se vean superadas y otras nuevas emerjan demandando un trabajo conjunto del científico con las comunidades, a partir del reconocimiento de una realidad conflictiva, abierta y condicionada por el territorio. Lo relevante es que si bien busca estrechar los vínculos comerciales al igual que otras iniciativas surgidas en este siglo, como por ejemplo, la Alianza del Pacífico (AP), lo hace a partir de concepciones diferentes respecto al desarrollo y la integración regional (Schaposnik y Pardo, 2013).

Por ello, da prioridad a un nuevo tipo de agenda social, poniendo en evidencia, en primer plano, el conflicto Estado-mercado, un conflicto vertebral que atraviesa los países, los procesos de integración regional y medularmente la economía social desde sus orígenes más remotos. La cuestión que parece dirimirse, entonces, es que si la balanza se inclina por el mercado, el "cómo" avanzar quedará sujeto a la lógica excluyente y selectiva de los actores que detenten más poder en ese ámbito; en tanto, con una mayor relevancia del Estado, se abre la posibilidad de ampliar la participación social y discutir el sentido del sendero del desarrollo. En consecuencia, se entiende como imprescindible un mayor involucramiento ciudadano y la participación de organizaciones sociales representativas de los pueblos de nuestra América (Schaposnik y Pardo, 2015).

En el camino hacia la construcción de una integración alternativa, en la que el rol transformador del Estado pasa a un primer plano, Petrocaribe propone una integración energética "importante en la promoción soberana de un proyecto autónomo, lo que significa recuperar soberanía sobre los recursos naturales y disponerlos en una lógica no mercantil, [desafiando a] ensayar un nuevo camino que reconstruya el imaginario originario en nuestra América", como vislumbra Gambina (2011, párr. 7).

La necesidad de una integración más amplia y profunda, que implicará también repensar la agenda social, se planteó también en la XLVI Cumbre del Mercosur realizada en julio del 2014 en Caracas. Allí se acordó promover la constitución de una zona económica complementaria (ZEC) con el ALBA-TCP y
Petrocaribe - incluyendo también a CARICOM - "con el objeto de dinamizar sus relaciones políticas y económicas, potenciando el desarrollo de un comercio complementario, justo y equilibrado que responda a los más altos intereses de desarrollo de los pueblos" (Mercosur, 2014). En la declaración adoptada se definen aspectos a tener en cuenta en las negociaciones, que apuntan al incremento del comercio de bienes originarios; la articulación entre empresas del sector público y privado; la definición de programas de cooperación conjunta para identificar y desarrollar proyectos de complementariedad económica; el diseño de mecanismos que aseguren un mayor equilibrio en el intercambio comercial con el fin de reducir las asimetrías económicas, la promoción del desarrollo de las microempresas y las pymes, la promoción de las cooperativas y la intensificación del intercambio.

\section{Economía social y solidaria: luces y sombras en la integración}

En los últimos años, han surgido nuevos actores (bancos éticos, organizaciones de comercio justo, empresas autogestionarias, redes de productores orgánicos o productores artesanales, etc.) que, sumados a los de mayor tradición (cooperativas, mutuales, asociaciones), caracterizan un sector específico de la economía. De tal modo, se da la coexistencia de aquello que en el continente europeo se denomina "economía social", con la "economía solidaria" que en América Latina pone énfasis en los lazos de solidaridad como estrategias de sobrevivencia y lleva adelante prácticas alternativas a las hegemónicas (Guerra, 2012).

Según Angulo (2011), la economía social y solidaria es "un modo de hacer economía en el que se evidencian comportamientos personales y colectivos centrados en criterios de solidaridad, mutualismo, cooperación y autogestión comunitaria, que pueden manifestarse y expandirse en diferentes sectores sociales y planos económicos" (p. 15) y en el cual su principal horizonte de acción, como señala Pastore (2010), está dado por "su finalidad social, su arraigo en comunidades territoriales, su forma de gestión autónoma y democrática y su perspectiva de sustentabilidad integral (económica, social, ambiental, intergeneracional)” (p. 2). Coraggio (2007), a su vez, avanza en destacar su capacidad transformadora "en dirección a otra economía, otro sistema socioeconómico, organizado por el principio de la reproducción ampliada de la vida de todos los ciudadanos-trabajadores, en 
contraposición con el principio de la acumulación de capital" (p. 37).

Aunque constituya un subsistema carente de autonomía absoluta y en muchos casos se subordine a la lógica del sistema capitalista, puede afirmarse que la economía social solidaria (Ess) prioriza la satisfacción de las necesidades individuales y la calidad de vida sobre la rentabilidad económica. En este subsistema es en el que situamos a las cooperativas, expresión histórica tradicional de la economía social junto con las mutuales, aun a sabiendas de que, por su carácter de empresas que interactúan en mercados competitivos y en un contexto de internacionalización de sus actividades, optan en muchos casos por prácticas que ponen en riesgo su identidad original.

Aun así, como sugieren Defourny y Develtere (2001), son capaces de realizar un aporte original y significativo en nuestras sociedades. Por un lado, "invirtiendo en los espacios donde las necesidades importantes están poco o nada satisfechas por las empresas privadas clásicas y por los poderes públicos; [por otro,] poniendo las esperanzas en las dinámicas participativas que, como la democracia, deben ser realimentadas sin cesar" (p. 76).

Su importancia en la vida y el desarrollo de los pueblos ha llevado a la oIT y a la onu a reconocer su importancia, señalando que se trata de organizaciones que deberían ser fomentadas y apoyadas porque constituyen una forma de organización de la propiedad alternativa, que privilegia a los sujetos sociales por encima del mercado. En lo esencial, alientan redes de solidaridad, valores y normas de beneficio colectivo, toma de decisiones democráticas, producción y distribución equitativa de bienes y servicios y sistemas de precios justos y de calidad, además de promover el empleo decente y la superación de la informalidad laboral (Schaposnik y Pardo, 2012; Pardo, 2012).

En su evolución y en las distintas cumbres presidenciales del ALBA-TCP, fueron reconocidas las cooperativas, la economía solidaria y otras formas de organización social, incluyéndolas al delinearse principios guía, acuerdos de cooperación y de complementación. Así, por ejemplo, se dispone que los países deberán "ejecutar inversiones de interés mutuo que pueden adoptar la forma de empresas públicas, binacionales, mixtas, cooperativas, proyectos de administración conjunta y otras modalidades de asociación que decidan establecer", dando prioridad a "las iniciativas que fortalezcan las capacidades de inclusión social, la industrialización de los recursos, la seguridad alimentaria, en el marco del respeto y la preservación del medio ambiente" (ALBA-TCP, 2006). A pesar de este reconocimiento, el sector no está incluido en la estructura institucional, como sí lo están los movimientos sociales.

También al firmarse el acuerdo para la constitución de ECOALBA se resalta que:

La distribución equitativa de las riquezas y el fomento de formas de propiedad populares, cooperativas y sociales de los medios de producción constituyen poderosas herramientas para asegurar la justicia social y el progreso de nuestras sociedades y sistemas económicos, [estableciendo la voluntad de] impulsar la participación de las unidades productivas comunales, indígenas originarias, campesinas, cooperativas, pequeñas y medianas empresas, de propiedad social, estatal y privada, y demás tipos de emprendimientos, en dicho proceso (xI Cumbre Ordinaria, 2012).

A partir de este reconocimiento, se constata un entramado de oportunidades para las cooperativas y organizaciones de la economía solidaria en general, ya que están contempladas en programas y proyectos como los financiados por el Banco del Alba; en convenios celebrados, tal es el caso del EcoAlba que las incluye dada su forma de propiedad para encadenamientos productivos; en el SUCRE, para el cual son parte de los nuevos actores del comercio justo, solidario y complementario (Schaposnik y Pardo, 2013); o en Petrocaribe, que participó en el 2014, junto con el Mercosur y el ALBA-TCP, en la constitución de una zona económica complementaria (ZEC) que incluye también a Caricom.

En la declaración adoptada en aquella oportunidad se propuso iniciar negociaciones para incrementar el comercio de bienes originarios; la articulación entre empresas del sector público y privado; la definición de programas de cooperación conjunta paraidentificar y desarrollar proyectos de complementariedad económica; el diseño de mecanismos que aseguren un mayor equilibrio en el intercambio comercial con el fin de reducir las asimetrías económicas; la promoción del desarrollo de las microempresas y las pymes; la promoción de las cooperativas; la intensificación del intercambio regional, en particular de los productos de mayor valor agregado, entre otros.

En principio, este tratamiento muestra una forma de inclusión ensamblada, distinta a la estudiada en otros procesos de integración como el Mercosur, en el que la captura de políticas depende de la acción colectiva en la estructura institucional a través de la Reunión Especializada en Cooperativas o la 
Comunidad Andina (CAN), en las cuales en los consejos consultivos solo participan los representantes del mundo del trabajo y los empresarios, o de la Unasur, iniciativa que planteó entre sus objetivos prioritarios la integración productiva y el establecimiento del Banco del Sur con miras a incluir en su financiamiento a las organizaciones de la economía social y solidaria (Pardo, 2012; Schaposnik y Pardo, 2011a, 2011b; Schaposnik, 2011).

También difiere de los objetivos de la Alianza para el Pacífico (AP) surgida formalmente en el 2012 con el fin de conformar un área de "integración profunda [mediante la] búsqueda progresiva de la libre circulación de bienes, servicios, capitales y personas" (Alianza del Pacífico, 2012), con especial énfasis en el Asia Pacífico, sustentado en políticas aperturistas acordes con la perspectiva del regionalismo abierto, compartidas por los gobiernos de esta iniciativa. En su organización institucional se destaca una instancia política (Reunión de Presidentes), el Consejo de Ministros y el Grupo de Alto Nivel, apoyados por grupos de trabajo sobre los distintos temas que propone el TLC de manera que su ejecución resulte eficaz. Desde ya, en consonancia con sus objetivos, entre sus prioridades no incluye a la economía social y solidaria ni las cuestiones sociales, como si sus soluciones pudieran devenir naturalmente a partir de la liberalización del comercio entre economías desiguales (Schaposnik y Pardo, 2014).

Parece necesario, entonces, siguiendo a Vaillancourt (2011), abrir una instancia para que las organizaciones de la economía social y solidaria puedan "expresar su voz entre aquellos otros actores al momento de la definición de las políticas y programas públicos” (p. 17). La construcción conjunta de políticas públicas requiere un Estado que "favorezca las formas de gobernabilidad abiertas que dan lugar a la participación de actores sociales que provienen de sectores no estatales" (p. 43) y un diseño institucional en los procesos de integración regional acorde. Tal como señala Prats (2003), de él depende la captura de la política por los grupos de interés porque "afecta al carácter de las políticas que, a su vez, también establecen reglas o marcos institucionales bajo los que tendrá lugar la toma de decisiones colectivas” (p. 245).

\section{Conclusiones}

El ALBA-TCP es una iniciativa transformadora en la senda de redefinir y resignificar los procesos de cooperación e integración existentes, lo cual lleva como premisa que para construir colectivamente cambios estructurales es necesario establecer nuevas categorías, nuevas agendas. Más allá de las dificultades y contradicciones, sus diversos mecanismos e instrumentos proponen caminos alternativos hacia una integración social y solidaria.

En este marco, se abren oportunidades para las organizaciones de la economía social y solidaria que podrán usufructuarlas en tanto se involucren e incidan para construir en conjunto nuevos canales de participación, aunque actualmente no estén incorporadas en su estructura institucional. Se podrán observar pasos concretos en tanto los gobiernos reciban las recomendaciones de la oIT sobre promoción y fomento a través de políticas públicas, hacia el cooperativismo y en general hacia la economía social y solidaria, tanto en su diseño como en el seguimiento de estas.

En cuanto a los movimientos sociales, participan en el ALBA-TCP aquellos que tienen capacidad de movilización popular, sostienen una concepción antiimperialista, antineoliberal y luchan por la emancipación de la región ${ }^{4}$. En ese sentido, entendemos que la incidencia es necesaria y coincidimos en afirmar que:

La co-construcción solidaria no es un lujo sino una necesidad para la democracia [y que] cuando los actores de la sociedad civil y de la economía social son olvidados o instrumentalizados en la relación con el Estado, las políticas públicas son empobrecidas (Vaillancourt, 2009, p. 17).

\section{Referencias}

ALBA-TCP. (2006). Acuerdo para la aplicación del ALBA-TCP. Documento de la III Cumbre Presidencial, La Habana, Cuba. Recuperado de http://alba-tcp.org/contenido/ acuerdo-para-la-aplicaci\%C3\%B3n-del-alba-tcp

ALBA-TCP. (2009a). Acta de Instalación del Consejo Social del ALBA-TCP. Primera Reunión de Ministros del Área Social. Recuperado de http://alba-tcp.org/contenido/ i-reunion-consejo-social

4 En las investigaciones realizadas por las autoras no se ha lle vado adelante la identificación de los actores sociales involucrados que permita determinar si algunas organizaciones de la economía social y solidaria - y en particular las cooperativas - participan. 
ALBA-TCP. (2009b). Estructura y funcionamiento ALBA-TCP. Documento de la viII de la Cumbre Presidencial, La Habana, Cuba. Recuperado de http://alba-tcp.org/ contenido/estructura-y-funcionamiento-del-alba-tcp

Alianza del Pacífico. (2012). Acuerdo Marco de la Alianza del Pacífico. Recuperado de https://alianzapacifico.net/ documentos/

Angulo, N. (2011). Economía social solidaria, mujeres y políticas públicas. En N. Angulo, M. Caracciolo, M. Foti, N. Sanchís, Economía social y solidaria. Políticas públicas y género. Recuperado de http://base.socioeco. org/docs/ess__pol_ticas_p_blicas_y_genero.pdf

Benzi, D. (2010). ¿En la hora de las definiciones? Una aproximación al ALBA al atardecer del neoliberalismo. Revista de Ciencias Sociales de la Universidad Iberoamericana, 10, 69-99.

Briceño, J. (2011). El ALBA como propuesta de integración. En J. Altmann (Ed.), ALBA: ¿Una nueva forma de Integración Regional? (pp. 19-83). Buenos Aires: Teseo.

Coraggio, J. L. (2007). Economía social, acción pública y política. Argentina: Ciccus.

Defourny, J. y Develtere, P. (2001). Orígenes y perfiles de la economía social en el Norte y en el Sur. En J. Defourny, P. Develtere y B. Fonteneau (Eds.), La economía social en el Norte y en el Sur (pp. 35-84). Buenos Aires: Corregidor.

Gambina, J. (2011, junio 20). Integración regional: un modelo en discusión. Página 12. Recuperado de http:// www.pagina12.com.ar/diario/economia/2-1704432011-06-20.html

Guerra, P. (2012). Las legislaciones sobre economía social y solidaria. Casos latinoamericanos y europeos. Documento de Trabajo N. ${ }^{\circ}$ 4, Facultad de Derecho, Universidad de la República. Recuperado de file://C:/Users/ USUARIO/Downloads/GUERRA,\%20Pablo\%20 (2012)\%20Las\%20legislaciones\%20sobre\%20econom $\%$ C3\%ADa\%20social\%20y\%20solidaria.\%20 Casos\%20latinoamericanos\%20y\%20europeos.\%20 DT\%20N\%C2\%BA\%204,\%20Carrera\%20de\%20Relaciones\%20Laborales,\%20Facultad\%20de\%20Derecho,\%20UdelaR.\%20Montevideo.pdf

Mercosur. (2014). Declaración conjunta de los estados partes del Mercado Común del Sur (Mercosur) para promover el establecimiento de una zona económica complementaria entre los Estados partes del Mercado Común del Sur (Mercosur), los países miembros de la Alianza Bolivariana para los Pueblos de Nuestra América (ALBA-TCP), los países miembros de Petrocaribe y los miembros de la Comunidad del Caribe (Caricom). Documento de la XLvi Cumbre, Caracas, Venezuela.
Pardo, E. C. (2012). Las cooperativas en la estructura jurídica institucional de la CAN y el Mercosur. En N. Mellado (Coord.), Instituciones, comercio y cooperación monetaria en la integración sudamericana: Sus efectos sobre la gobernabilidad regional. Buenos Aires: Lerner.

Pastore, R. E. (2010). Un panorama del resurgimiento de la economía social y solidaria en Argentina. Revista de Ciencias Sociales, 2(18), 47-74. Recuperado de http:// base.socioeco.org/docs/5138b6c063f68_1_.pdf

Petróleos de Venezuela, S. A. [PDVsA]. (2005). Estatutos. Recuperado de http://www.pdvsa.com/index.php? tpl=interface.sp/design/readmenu.tpl.html\&newsid_ obj_id $=720$ \&newsid_temas $=48$

Prats, J. O. (2003). El concepto y el análisis de la gobernabilidad. Revista Instituciones y Desarrollo, 14-15, 239-269. Recuperado de http://www.ses.unam.mx/docencia/ 2007II/Lecturas/Mod3_Oriol.pdf

Schaposnik, C. R. (2011). Financiamiento solidario en Nuestramérica. Perspectivas para las cooperativas con los Bancos del Sur y del Alba. Revista Densidades, 7, 85-96.

Schaposnik, C. R. y Pardo, E. C. (2009). Financiamiento y desarrollo en Unasur. En N. Mellado (Coord.), Mercosur y Unasur, ¿hacia dónde van? (pp. 249-283). Buenos Aires: Lerner.

Schaposnik, C. R. y Pardo, E. C. (2011a). Las cooperativas en la co-construcción de institucionalidad en el Mercosur y su proyección hacia otros acuerdos de integración regional. En Seminario Internacional La co-construcción de conocimientos y prácticas sobre la economía social y solidaria en América Latina y Canadá. Buenos Aires: Centro de Estudios de Sociología del Trabajo, Facultad de Ciencias Económicas de la Universidad de Buenos Aires.

Schaposnik, C. R. y Pardo, E. C. (2011b). Bank of the South, a Possible Alternative for Funding South American Development. En P. Ciriec y B. Luc, Contemporary Crisis and Renewal of Public Action. Towards the Emergence of a New Form of Regulation (pp. 301-318). Belgium: Peter Lang S. A.

Schaposnik, C. R. y Pardo, E. C. (2012). La integración regional: oportunidades y desafíos para el cooperativismo latinoamericano. En VII Encuentro de Investigadores Latinoamericanos de la Alianza Cooperativa Internacional "Innovación social y desarrollo cooperativo en el marco del año internacional del cooperativismo". Santiago de Chile: ACI.

Schaposnik, C. R. y Pardo, E. C. (2013). El ALBA-TCP y su aporte en la construcción de una Nueva Arquitectura 
Financiera Regional. En vi Jornadas de Economía Crítica. Economía Política y Política Económica. Debates actuales sobre el Estado y los procesos sociales latinoamericanos (CD-ROM). Mendoza: Universidad Nacional de Cuyo.

Schaposnik, C. R. y Pardo, E. C. (2014). ALBA-TCP y AP: visiones divergentes sobre la integración y el comercio. Densidades, 15, 57-70.

Schaposnik, C. R. y Pardo, E. C. (2015). Petrocaribe y ALBA-TCP. Dos pilares de la política energética de Venezuela hacia la región. En N. Mellado (Ed.), Estrategias de inserción internacional e integración latinoamericana en el siglo XXI (pp. 219-241). Buenos Aires: Lerner.

SEla (2013). Acuerdo de Cooperación Energética Petrocaribe. Caracas: Secretaría Permanente del sela. Disponible en http://www.sela.org/media/265370/t0236 00005381-0-di_no_3_acuerdo_de_cooperacion_petrocaribe-final_doc_rev_21-8-13.pdf

Silva, M. C. (2011). La Alianza Bolivariana para las Américas (ALBA): aspectos de seguridad y defensa y elementos de participación social. En A. Serbin (Coord.), De la ONU al ALBA: Prevención de conflictos y espacios de participación ciudadana (pp. 241-291). Buenos Aires: Icaria-CRIES.

Solón, P. (2006). TLC vs TCP. Entrevista en página web. Recuperado de http://www.aporrea.org/tecno/n77161.html

Svampa, M. (2012). Pensar el desarrollo desde América Latina. En: A. Acosta et al., Renunciar al bien común: Extractivismo y (pos) desarrollo en América Latina. Buenos Aires: Mardulce.

Vaillancourt, Y. (2009). La democratización de las políticas públicas: una mirada canadiense y québequense. En $\mathrm{F}$. Mariñez Navarro y V. Garza Cantú (Eds.), Democracia y Política Pública: del análisis a la implementación. México: Editorial Miguel Ángel Porrúa. Recuperado de https://periferiaactiva.files.wordpress.com/2011/09/ yvesvdemocratiz.pdf

Vaillancourt, Y. (2011). La economía social en la co-producción y la co-construcción de las políticas públicas. Revista del Centro de Estudios de Sociología del Trabajo, III, 29-67. 